\title{
PREVALENCE OF CRYPTOSPORIDIUM INFECTION IN CATTLE IN MAIDUGURI, NORTH EASTERN NIGERIA
}

\author{
S. G. Adamu ${ }^{1}$, N. B. Adamu ${ }^{1}$, A. U. Aliyu ${ }^{3}$, N. N. Atsanda ${ }^{1}$, F. B. Mustapha ${ }^{1}$, Y. A. Muhammad ${ }^{2}$ and \\ G. A. Umaru ${ }^{4}$
}

${ }^{1}$ Department of Veterinary Public Health and Preventive Medicine, Faculty of Veterinary Medicine University of Maiduguri, Nigeria; ${ }^{2}$ Department of Veterinary Microbiology and Parasitology, Faculty of Veterinary Medicine

University of Maiduguri, Nigeria; ${ }^{3}$ Ministry of Animal and Fisheries Development Damaturu, Yobe State, Nigeria; ${ }^{4}$ Department of Animal Health, College of Agriculture, Jalingo, Taraba State, Nigeria

\begin{abstract}
A study was carried out to survey the prevalence of Cryptosporidium infection in cattle in Maiduguri, Northeastern Nigeria. A total of four hundred (400) fecal samples from cattle were randomly collected and examined for the presence of Cryptosporidium sp. oocysts using the modified Ziehl-Neelsen (MZN) staining method. The results showed that the overall prevalence of infection was $22.3 \%$, with an infection rate of $23.4 \%$ in adult cattle and $19.1 \%$ in young cattle, respectively. There was no statistical significant difference $(\mathrm{P} \leq 0.05)$ between the age groups, with (OR: $1.298 ; 95 \% \mathrm{CI}$ : 0.7507-2.245). Out of 89 positive samples, $21.2 \%$ were male and $25.0 \%$ were female, respectively. There was no statistical significant difference $(\mathrm{P}>0.05)$ between the sex, with (OR: 0.8062; 95\% CI: 0.4828-0.346). It was concluded that Cryptosporidium sp. infection is prevalent in Nigeria; and cattle could serve as reservoirs for the zoonotic infection in humans.
\end{abstract}

Key words: Cryptosporidium sp., cattle, maiduguri, oocyst, prevalence, Nigeria

\section{INTRODUCTION}

Cryptosporidium is an apicomplexan intestinal protozoon, which infects animals and humans gastrointestinal tract and causes cryptosporidiosis (Carey et al., 2004; Huang and White, 2006). The infection causes cryptosporidial diarrhea, which is commonly a short-lasting benign diarrhea. In addition it can cause severe diarrhea in immunocompromised host (Huang and White, 2006; Collinet-Adler and Ward, 2010). Some of the zoonotic Cryptosporidium species (C. parvum, C. meleagridis, and C. canis) usually causes self-limiting diarrhoea in human and animals and could be a great public health concern worldwide (Minas et al., 1994; De Graaf et al., 1999; Castro-Hermida et al., 2002; Graczyk et al., 2003; Joachim, 2004; Caccio, 2005). Cryptosporidiosis is more severe in newborn animals and causes severe diarrhea that is sometimes accompanied with anorexia, reduced milk intake, dehydration, growth retardation, stiffness, hyperpnoea, slow gait and depression (Casemore et al., 1997; Fayer, 2004). Although the adult animals are generally refractory to infection, infected animals can act as asymptomatic carriers and shed large numbers of oocysts into the environment and remain a main source of infection to other domestic and wild animals (Xiao et al., 1993).

Cattle cryptosporidiosis is widespread and studies have shown a wide range of oocyst shedding dynamics depending on the age, clinical situation and breeding system of the animals (Maldonado-Camargo et al., 1998). Although cattle are the most common domestic animals and the major meat-producing animals in Nigeria with economic value, there is no readily available data on cryptosporidiosis in cattle in Nigeria. Cattle are being reared and come close to human sources of water and farms during grazing due to semi-intensive management systems. The potential hazard that $C$. parvum from cattle poses to public health in Nigeria, therefore, makes it necessary to investigate the prevalence of cattle cryptosporidiosis and also understand the factors that lead to the transmission and spread of infection in animals and humans.

This study is aimed at investigating the prevalence of Cryptosporidium infection in cattle in Maiduguri, Northeastern Nigeria, with the view that this knowledge will serve as a basis for screening the Cryptosporidium species in cattle in Nigeria and to facilitate further studies on the zoonotic transmission of the disease from animals to humans.

*Corresponding e-mail address: gsadamu@yahoo.com

Copyright $(2015$ Bangladesh Society for Veterinary Medicine

All rights reserved 0322/2015 


\section{S. G. Adamu and others}

\section{MATERIALS AND METHODS \\ Study Area}

Borno State is situated in the Northeastern part of Nigeria. The state lies between latitude $10^{\circ} \mathrm{N}$ and $13^{\circ} \mathrm{E}$ and longitude $12^{\circ} \mathrm{N}$ and $15^{\circ} \mathrm{E}$. The state has a total area of 69,436 square kilometers, with a population of 4,151,161 people. It occupies the greatest part of the Chad Basin. The state has two vegetation zones viz: Sahel in the North which is hot and with severe desert encroachment covering most of the Chad Basin areas and Sudan Savannah in the South which is slightly milder. The rainy season normally begins from June- September in the North and May-October in the South with relative humidity of $49 \%$. Borno State shares boundaries with the Republic of Niger to the North, Chad Republic to the North-east and Cameroon to the East. Within the country, the state shares border with Adamawa to the south, Yobe to the West, Bauchi and Gombe to the South-west (GSN, 1994).

\section{Sample Collection, Transportation and Storage}

A total of four hundred (400) fecal samples from cattle comprising of 175 male and 225 females of both young and adults were collected directly from the rectum of each animal by means of disposable plastic bag and emptied into a wide-mouthed disposable plastic container. The fecal samples were transported to the laboratory and preserved in $75 \%$ alcohol at room temperature until processed (Jongwutiwes et al., 2002).

\section{Cryptosporidiumoocyst detection}

The collected fecal samples of each animal were examined by direct smear techniques. To determine oocysts shedding, the negative faecal samples by direct smear examination were concentrated by centrifugal sedimentation (2,500 rpm for $2 \mathrm{~min}$ ) and Clayton-Lane flotation techniques using standard Sheather solution (sg 1.12) (Soulsby, 1982; Hendrix, 1998). The presence of Cryptosporidium- like oocysts in all samples was confirmed by modified Ziehl-Neelsen (MZN) staining (Henricksen and Polenz, 1981). The diameter of 100 Cryptosporidium like oocysts of each infected cattle was measured at 1,000 $\times$ magnification. Each positive sample was considered when at least one oocyst with the correct morphologic characters was observed (Cryptosporidium - like oocysts were 4-6 $\mu \mathrm{m}$ and spherical containing a residuum, sporozoites and usually within a clear halo, against a blue background) (Soulsby, 1982; Baxby et al., 1984).

\section{Statistical analysis}

The data were analysed using Chi-square test with GraphPad in Stat (statistical) software. A Chi-square test was used to compare the differences in prevalence of Cryptosporidium oocysts between age-groups of cattle at a $5 \%$ level of significance.

\section{RESULTS AND DISCUSSION}

The prevalence of cryptosporidiosis was studied on the basis of the detection of oocysts in the fecal samples collected from Maiduguri abattoir. Out of 400 fecal samples screened, $89(22.3 \%)$ animals were found positive for cryptosporidiosis by modified Ziehl-Neelsen (MZN) staining method. The infection rate with Cryptosporidium spp. was higher in adult cattle with the prevalence of $23.4 \%$ (68/290) while in the young calves the prevalence rate lower $19.1 \%(21 / 110)$ respectively. There was no statistical significant difference $(\mathrm{P}>0.05)$ between the age group (Table 1). Some of the infected animals showed wasting, diarrhoea and debility. Older cattle with shedding oocysts in faeces did not show symptoms of cryptosporidiosis. Based on sex distribution, thehighest prevalence was found in female $25.0 \%$ (28/112) while in the male the prevalence was lower $21.2 \%$ $(61 / 288)$ respectively. There was no statistical significant difference $(\mathrm{P}>0.05)$ between the sex of the animals tested (Table 2).

Table 1. Prevalence of Cryptosporidium infection in cattle with age group in Maiduguri, Northeastern Nigeria

\begin{tabular}{|c|c|c|c|c|c|c|c|}
\hline \multirow[t]{2}{*}{ Age } & \multirow[t]{2}{*}{ Number Examined } & \multirow[t]{2}{*}{ Number Infected } & \multirow[t]{2}{*}{ Percentage } & \multirow[t]{2}{*}{ OR } & \multirow[t]{2}{*}{$\mathrm{P}$ value } & \multicolumn{2}{|c|}{$95 \% \mathrm{CI}$} \\
\hline & & & & & & Lower & Upper \\
\hline Adult & 290 & 68 & 23.4 & & & & \\
\hline Young & 110 & 21 & 19.1 & 1.298 & 0.4232 & 0.7507 & 2.245 \\
\hline Total & 400 & 89 & 22.3 & & & & \\
\hline
\end{tabular}


Prevalence of Cryptosporidium infection in Cattle

Table 2. Prevalence of Cryptosporidium infection in cattle with sex in Maiduguri, Northeastern Nigeria

\begin{tabular}{|c|c|c|c|c|c|c|c|}
\hline Sex & Number Examined & Number Infected & Percentage & OR & $\mathrm{P}$ value & \multicolumn{2}{|c|}{$95 \%$ CI } \\
\hline & & & & & & Lower & Upper \\
\hline Male & 288 & 61 & 21.2 & & & & \\
\hline Female & 112 & 28 & 25.0 & 0.8062 & 0.4897 & 0.4828 & 1.346 \\
\hline Total & 400 & 89 & 22.3 & & & & \\
\hline
\end{tabular}

The overall prevalence (22.3\%) of Cryptosporidium in cattle obtained in this study is consistent with that observed in cattle from South West parts of Nigeria 23.4\% (Ayinmode and Fagbemi, 2010),from other parts of the world:19\% of calves in Spain (Panciera et al., 1971), 20\% of calves in Canada (O'donoghue, 1995); 1936\% of cattle in Germany (Joachim et al., 2003); 35\% of calves in the United States of America (Santin et al., 2004); and 24.2\% of cattle in Bangalore, South India (Mallinath et al., 2009. The result of this study thus implies that Cryptosporidiuminfection in cattle, as well as the possible risk of transmission to humans by cattle, is important in the study area as it is elsewhere in the world. Therefore, considerable attention should be paid to preventing the spread of the infection.

Based on this study, it was observed that there was no statistical significant difference between the rate of the infection in cattle based on age distribution $(\mathrm{P}>0.05)$, though the infection rate was higher amongst adults cattle than the younger cattle. Similarly there was no statistical significant difference between the rateof infection and sex distribution of cattle $((\mathrm{P}>0.05)$, though the infection rate was higher among female cattle than male.

This study was in contrast with those made by Ongerth and Stibbs (1989), Shobhamani (2005), Jayabal and Ray (2005), Roy et al. (2006), and Mehdiazami (2007) who reported higher rates of infection among calves thanadult cattle. The study indicated that the adult animals were highly susceptible to infection with cryptosporidiosis compared to young animals. This could be as a result of other factors likemanagement practice, concurrent infection, seasonal variation, and others than the sole impact of Cryptosporidium species. From these findingsefforts should be directed towards the diagnosis and prevention of Cryptosporidiosis in Nigeria so as to prevent the transmission of the disease to human beings.

\section{REFERENCE}

1. Ayinmode AB and Fagbemi BO (2010). Prevalence of Cryptosporidium infection in cattle from South Western Nigeria. Veterinarski Arhives 80: 723 - 731.

2. Baxby D, Blundell $\mathrm{N}$ and Hart CA (1984). The development and performance of a simple sensitive method for the detection of Cryptosporidium oocysts in faeces. Journal of Hygiene Cambridge 99: 317-323.

3. Caccio` SM, Thompson RC and McLauchlin J (2005). Unravelling Cryptosporidium and Giardia epidemiology. Trends in Parasitology 21: 430-437.

4. Carey CM, Lee H and Trevors JT (2004). Biology, persistence and detection of Cryptosporidium parvum and Cryptosporidium hominis oocyst. Water Research 38: 818-862.

5. Casemore DP, Wright SE and Coop RL (1997). Cryptosporidiosis-human and animal epidemiology. In: Fayer, R (Ed): Cryptosporidium and cryptosporidiosis. CRC Press, Boca Raton, FL, 65-92.

6. Castro-Hermida JA, Gonzalez-Losada YA and Ares-Mazas E (2002). Prevalence and risk factors involved in the spread of neonatal bovine cryptosporidiosis in Galicia (NW Spain). Veterinary Parasitology 106: 1-10.

7. Collinet-Adler S and Ward H (2010). Cryptosporidiosis environmental, therapeutic, and preventive challenges. European Journal of Clinical Microbiology and Infectious Diseases 29: 927-935.

8. De Graaf DC, Vanopdenbosch E, Ortega-Mora LM, Abbasi H and Peeters JE (1999). A review of the importance of cryptosporidiosis in farm animals. International Journal for Parasitology 29: 1269-1287.

9. Fayer R (2010). Taxonomy and species delimitation in Cryptosporidium. Experimental Parasitology 124: 90-97.

10. Geographical Survey of Nigeria (GSN) (1994). The survey of the Nigerian's climatic date, Cited in Dura MM (2001): Physical, Environment and Development: a study of Borno Region. In: Ogunica OI, Daura MM, and Balami D (eds). Environment and Development issues in Sub-Saharan Africa, Seminar services. Faculty of Social Sciences, University of Maiduguri 6: 35-47.

11. Graczyk TK, Grimse BH, Knight R, Dasilva AJ, Pieniazek NJ and Veal DA (2003). Detection of Cryptosporidium parvum and Giardia lamblia carried by synanthropic flies by combined fluorescent in situ hybridization and a monoclonal antibody. American Journal of Tropical Medicine and Hygiene 68: 228-232.

12. Hendrix CM (1998). Diagnostic Veterinary Medicine. $2^{\text {nd }}$ edition. Mosby Publishers, St. Louis, pp. $257-259$. 


\section{S. G. Adamu and others}

13. Henricksen SA and Polenz JF (1981). Staining of Cryptosporidia by modified Ziehl-Neelsen technique. Acta Veterinaria Scandinavica 22: 594-596.

14. Huang DB and White AC (2006). An updated review on Cryptosporidium and Giardia. Gastroenterology of Clin North Am 35: 291-314.

15. Jayabal L and RAY DD (2005). Cryptosporidial infection in cattle and buffaloes. Journal of Veterinary Parasitology 19: 165 - 166 .

16. Joachim A, Krull T, Schwarzkopf J and Daugschies A (2003). Prevalence and control of bovine cryptosporidiosis in German dairy herds. Veterinary Parasitology 112: 277 - 288.

17. Joachim A (2004). Human cryptosporidiosis: an update with special emphasis on the situation in Europe. Journal of Veterinary Medicine B, Infectious Diseases and Veterinary Public Health 51: 251-259.

18. Jongwutiwes S, Tiangtip R, Yentakarm S and Chantachum N (2002). Simple method for long-term copropreservation of Cryptosporidium oocysts for morphometric and molecular analysis. Tropical Medicine and International Health 7: 257 - 264.

19. Maldonado-CamargoS, Atwill ER, Saltijeral-Oaxaca JA and Herreraalonso LC (1998). Prevalence of and risk factors for shedding of Cryptosporidium parvum inHolstein Freisian dairy calves in central Mexico. Preventive Veterinary Medicine 36: 95 - 107.

20. Mallinath RHK, Puttalakshmamma GC, Ananda KJG and Placid ED (2009). Studies on the prevalence of cryptosporidiosis in bovines in organized dairy farms in and around Bangalore, South India, Veterinarski Arhiv 79: $461-470$.

21. Mehdiazami M (2007). Prevalence of Cryptosporidium infection in cattle in Isfahan, Iran. Journal of Eukaryotic Microbiology 54: 100 - 102 .

22. Minas A, Koutsoukou-Hartona W and Papasavvas M (1994). Epidemiological survey of diarrhoeic faeces of lambs and kids for cryptosporidial oocysts in the Larissa region. Bulletin of the Hellenic Veterinary Medical Society 44: $112-114$.

23. O'donoghue PJ (1995). Cryptosporidiumand cryptosporidiosis in man and animals. International Journal of Parasitology 25: 139-195.

24. Ongerth E and Stibbs H (1989). Prevalence of Cryptosporidium infection in dairy calves in Western Washington. American Journal of Veterinary Resources 50: 1069 - 1070.

25. Panciera RJ, Thomassen RW and Gardner FM (1971). Cryptosporidial infection in a calf. Veterinary Pathology 8: 479-484.

26. Roy SS, Pramanik AK, Batabyal S, Sarkar S and Das P (2006). Cryptosporidiosisan important zoonotic disease: A review article. Intas Polivet 7: 432-436.

27. Santin M, Trout JM, Xiao L, Zhou L, Greiner E andFayer R (2004). Prevalence and age-related variation of Cryptosporidium species and genotypes in dairy calves. Veterinary Parasitology 122: 103 - 117.

28. Shobhamani B (2005). Epidemiological studies on diarrhoea in calves with particularreference to diagnosis and treatment of cryptosporidiosis. Journal of Veterinary Parasitology 19: 77.

29. Soulsby EJL (1982). Helminths, Arthropods and Protozoa of domesticated animals, $7^{\text {th }}$ edition. Bailliere Tindall London.

30. Xiao L, Herd RP and Rings DM (1993). Diagnosis of Cryptosporidium on a sheep farm with neonatal diarrhea by immunofluorescence assays. Veterinary Parasitology 47: 17-22. 